\title{
Estimation of some immunoglobulins classes and innate immunity parameters in BOM cases
}

\begin{abstract}
Immune response against OM infections depends mainly on Humoral mediated Immunity (HMI). From this scientific fact, the present study took care with the estimation of some immunological parameters related to these infections immunological response. Total W.B.C.s count was estimated. Furthermore Radial Immune Diffusion (RID) method was used in determination of Immunoglubulins IgG, IgM and IgA; also complement components $\mathrm{C} 3$ and $\mathrm{C} 4$ levels were estimated using Endoplate kits too. Results: OM Infections resultant from gram positive cocci increased total W.B.Cs counts, IgG, IgM, IgA, C3 and C4 complement components levels; in non-immunologicaly compromised patients comparing with the values of the peoples of control groups for all the parameters that estimated. Conclusions: Otitis media is a common infection in both children and adults. Gram positive suppurative OM caused; significant elevations in Total W.B.C.s counts, Immunoglubulins IgG, IgM and IgA and the complement components $\mathrm{C} 3$ and $\mathrm{C} 4$. Since HMI is the immunological response against these infections.
\end{abstract}

Keywords: OM infections, RID, HMI, IgG, humoral mediated immunity; IgM, IgA, total WBCs count, gram positive cocci
Volume 5 Issue I - 2017

\author{
Weam Saad Al Hamadany \\ College of Science, Al-Muthana University, Iraq
}

Correspondence: Weam Saad Al-Hamadany, College of Science, Al-Muthanna University, Samawah Governorate, Iraq, Tel 964791000000, Email dr.weam20I3@yahoo.com

Received: October 02, 2016 | Published: January 12, 2017
Abbreviations: $\mathrm{CG}(\mathrm{s})$, controls group(s); $\mathrm{CMO}$, chronic otitis media; ENT Ear, nose and throat; HMI, humoral mediated immunity; OM, otitis media; PG(s), patients group(s); PMNs, polymorphnucleous cells; RID, radial immune diffusion; RTI(s), respiratory tract infection(s); W.B.C.s, white blood cells

\section{Introduction}

Otitis media $(\mathrm{OM})$ infections represent a serious problem for many peoples, especially children. ${ }^{1}$ Recurrent suppurative OM with discharge, pain, and hearing impairment are the most common symptoms of this disease. Complicated cases may develop deafness. ${ }^{2}$ Gram positive cocci bacteria are the predominant pathogens responsible for such infections; pointing to Staphylococcus aureus and Streptococcus pneumonia. ${ }^{3-5}$ The complications upon OM infections made this disease very important, since when left untreated; the infection may spread to the surrounding tissues causing Mastoiditis, Brain abscess and Meningitis mainly in children and patients with impaired immune system. Prolonged chronic otitis media (COM) in children lead to problems in speech and social skills. ${ }^{6}$

Immune response against $\mathrm{OM}$ infections depends mainly on humoral mediated immune response (HMI). It starts with local inflammation at the site of pathogen invasion. Polymorphnucleous cells (PMNs) arrive combined with cytokines production and release; e.g. IL-1. These events end with specific antibodies production. Especially IgA; since sIgA plays a major role in the protection of body mucosal surfaces against bacterial colonization and infections. ${ }^{?}$

Pyogenic cocci bacteria like Staphylococcus aureus and encapsulated Streptococcus pneumoniae are able to resist body defenses by escaping phagocytosis, releasing enzymes and toxins. That will lead to W.B.Cs death and pus forming due to colonization of pathogen. Any defect in body immune system can cause recurrent suppurative OM infections that are usually called COM infections. ${ }^{4,8}$

\section{Materials and methods}

Patients: Otitis media cases were collected from the outpatients of (Ear, Nose and Throat) ENT Dep. Al-Numan Hospital in Baghdad
(2000-2006). The patients were clinically diagnosed by ENT physicians. A total of (60) OM cases were collected. They were infected with gram positive bacteria as causative pathogens as single or mixed infections. Bacteriological identification for them was done by the microbiological laboratories in the same hospital mentioned. ${ }^{2,5}$

Controls: Healthy volunteer people represented controls; they were (30) individuals taken randomly with no clinical signs for any disease. Whereas, ages were taking in account during controls collection as shown in Table 1. Smokers were avoided and no woman during menstruation period was involved as recommended by. ${ }^{9}$

Clinical specimens collection: A total of (5) ml blood sample was taken from all patients and controls by venipuncture.

Clinical specimens' treatment: Each blood sample was divided into two parts. One $\mathrm{ml}$ was put in EDTA tubes (whole blood) and kept in the refrigerator $\left(4^{\circ} \mathrm{C}\right)$. The second part $(4 \mathrm{ml})$ was used to separate serum after clotting; obtained serum was kept in freezer $\left(-20^{\circ} \mathrm{C}\right)$ until used. $^{9}$

Total W.B.C.s counts: whole blood was used in total W.B.C.s count estimation using Hemocytometer chamber as in. ${ }^{9}$

Immunoglubulins and complement components estimation: Antibodies $\operatorname{IgG}, \operatorname{IgM}$ and $\operatorname{IgA}$ and complements $\mathrm{C} 3$ and C4. These parameters were estimated using Endoplate Kits. The method of Radial Immunodiffusion (RID) was the Immunological Assay depended by the kit manufacturing company (Sanofi/ Italy). After serum samples application on the specific wells in plates, the antibodies and complement components diffused in the agarose gel. The gel contains a monospecific antiserum against the $\mathrm{Ab}$ class or complement component under test. Then precipitation zoon will form and able to be read after incubation (the leaflet of kit and 7).

Statistical analysis of data: All results that obtained for cases and controls were statistically analyzed using mean calculations (M) and standard Error (SE) using Statistical Analysis System SAS (2000). Each group results were compared with the other group's results using student t-test to find the significance of probability level (P) of 
increase or decrease for all the studied parameters, the level $(p \leq 0.05)$ was the level of significance ${ }^{10}$.

\section{Results}

The (60) OM patients included in this study were infected with gram positive cocci; Bacteriological culturing and identification was accomplished by microbiology laboratories in the same hospital. There were (49) patients (81.6\%) among them infected with Staphylococcus aureus. And 11 patients (18.3\%) were infected with Streptococcus pneumonia.

The total (60) Patients were divided into 6 groups according to age; also the (30) controls had the similar distribution; (the patients group (PG1) involved the youngest patient with three months age only). Each group results were compared with the similar age group of controls as shown in Table 1.

Generally; all patients' ages ranged (4-60)years while controls ranged (10-58)years. There were $26(43.3 \%)$ males and $34(56.7 \%)$ females recorded among patients, while controls represented 13 females and 17 males. Patients recorded $86.6 \%$ with chronic Otitis
Media (COM), while Acute Otitis Media (AOM) recorded (13.4\%) from total (60) cases.

Total W.B.C.s results are shown in Table 2 whereas PG5 recorded a significant increase $(\mathrm{P} \leq 0.5)$ comparing with $\mathrm{CG} 5$, other groups results increased but in significantly. The depended range of normal values was as in. ${ }^{11}$

The Endoplates (RID) results are shown in Table 3, Figure 1, IgG values increased significantly $(\mathrm{P} \leq 0.5)$ in all groups except $\mathrm{PG} 4$ which increased insignificantly comparing with CG5 mean value. The values of IgM increased significantly in all PG5 except PG2 which increased insignificantly, comparing with CG5, IgA values increased in PG4 and PG6 significantly $(P \leq 0.5)$ and insignificantly in $P G 2,3$ and 5 . While the mean of PG1 values decreased insignificantly.

Complement components $\mathrm{C} 3$ and $\mathrm{C} 4$ results are shown in Table 2. The complement $\mathrm{C} 3$ levels increased in all PGs outcomes. But, in PGs $1,2,3$ and 4 the elevation was significant $(\mathrm{P} \leq 0.5)$ comparing with CGs. The complement $\mathrm{C} 4$ values increased significantly $(\mathrm{P} \leq 0.5)$ in PGs 3, 4 and 5 while other groups increased insignificantly comparing with CGs.

Table I Otitis Media Patients and Control Groups with Age Ranges distributed according to Ages and Cases number

\begin{tabular}{llllll}
\hline No. & Age Range & Patients Group & No. of Cases & Control Groups & No. of Controls \\
\hline I & $\leq 10$ & PGI & 3 & CGI & 5 \\
\hline 2 & $20-$ Nov & PG2 & 6 & CG2 & 5 \\
\hline 3 & $21-30$ & PG3 & 16 & CG3 & 5 \\
\hline 4 & $31-40$ & PG4 & 18 & CG4 & 5 \\
\hline 5 & $41-50$ & PG5 & 13 & CG5 & 5 \\
\hline 6 & $51-60$ & PG6 & 4 & CG6 & 5 \\
\hline
\end{tabular}

Table 2 Total WBCs, Complement Components $C 3$ and $C 4$ values obtained for all groups, $(M \pm S E)$

\begin{tabular}{|c|c|c|c|c|c|c|c|}
\hline \multirow[t]{2}{*}{ No. } & \multirow[t]{2}{*}{ Age Range } & \multicolumn{2}{|c|}{ Total W.B.C.s count $\times 103$} & \multicolumn{2}{|c|}{ Complement C3 } & \multicolumn{2}{|c|}{ Complement C4 } \\
\hline & & PG & CG & PG & CG & PG & CG \\
\hline 1 & $\leq 10$ & $6.3 \pm 0.1$ & $10 \pm 0.01$ & $213.0 \pm 19.3^{*}$ & $117 \pm 0.02$ & $36.9 \pm 6.6$ & $26.8 \pm 1.8$ \\
\hline 2 & 20-Nov & $7.2 \pm 0.6$ & $6.9 \pm 0.5$ & $188.0 \pm 23.0 *$ & $137 \pm \mid 4.1$ & $35.2 \pm 7.9$ & $31.8 \pm 1.8$ \\
\hline 3 & $21-30$ & $8.7 \pm 1.5$ & $8.6 \pm 1.1$ & $178.0 \pm 36.2^{*}$ & $142 \pm 7.7$ & $45.9 \pm 11.1 *$ & $33.3 \pm 5.6$ \\
\hline 4 & $31-40$ & $8.4 \pm 2.5$ & $8.9 \pm 0.5$ & $194.9 \pm 44.4 *$ & $169 \pm 20.1$ & $45.1 \pm 12.8^{*}$ & $38.6 \pm 1.9$ \\
\hline 5 & $4 I-50$ & $9.0 \pm 2.1^{*}$ & $8.3 \pm 0.1$ & $175.8 \pm 19.8$ & $166 \pm 4.2$ & $39.7 \pm 9.7$ & $31.9 \pm 3.7$ \\
\hline 6 & $51-60$ & $8.8 \pm 0.7$ & $9.5 \pm 0.3$ & $189.0 \pm 28.8$ & $|6| \pm 1 \mid .3$ & $37.2 \pm 12.3$ & $32.0 \pm 7.4$ \\
\hline \multicolumn{2}{|c|}{ Normal Range } & \multicolumn{2}{|c|}{$(4.3-\mathrm{II}) \times 103 \mathrm{cell} / \mathrm{ml}$} & \multicolumn{2}{|c|}{$(|0|-\mid 86) \mathrm{mg} / \mathrm{dl}$} & \multicolumn{2}{|l|}{$(16-47) \mathrm{mg} / \mathrm{dl}$} \\
\hline
\end{tabular}

Table 3 The Immunoglubulins IgG, IgM, and IgA values obtained for all groups, $(M \pm S E)$

\begin{tabular}{llll}
\hline No. & Age Range & IgG & \\
\hline & & PG & CG \\
\hline 1 & $\leq 10$ & $1450.0 \pm 137.8^{*}$ & $1004.0 \pm 102.0$ \\
2 & $20-N o v$ & $1687.2 \pm 210.0^{*}$ & $1399.5 \pm 220.0$ \\
3 & $21-30$ & $1832.0 \pm 33.7^{*}$ & $1346.0 \pm 144.2$ \\
4 & $31-40$ & $1942.9 \pm 662.5$ & $1666.0 \pm 156.9$ \\
5 & $41-50$ & $1576.9 \pm 287.0^{*}$ & $1226.0 \pm 313.9$ \\
6 & $51-60$ & $1968.8 \pm 458.6^{*}$ & $1450.0 \pm 148.5$ \\
Normal Range & $(844-1912) \mathrm{mg} / \mathrm{dl}$ & \\
\hline
\end{tabular}

\begin{tabular}{llll} 
IgM & \multicolumn{3}{l}{ IgA } \\
\hline PG & CG & PG & CG \\
$190.3 \pm 43.8^{*}$ & $94.0 \pm 28.0$ & $183.3 \pm 56.9$ & $187.2 \pm 2.34$ \\
$205.2 \pm 139.0$ & $108.5 \pm 10.6$ & $250.0 \pm 27.3$ & $276.5 \pm 17.8$ \\
$224.3 \pm 61.7^{*}$ & $113.0 \pm 26.9$ & $305.5 \pm 95.4$ & $165.5 \pm 23.0$ \\
$209.0 \pm 129.8^{*}$ & $120.5 \pm 28.0$ & $360.3 \pm 115.6^{*}$ & $201.5 \pm 13.5$ \\
$204.0 \pm 66.5^{*}$ & $116.5 \pm 10.6$ & $256.7 \pm 82.0$ & $244.5 \pm 21.9$ \\
$244.3 \pm 131.9^{*}$ & $136.0 \pm 5.7$ & $400.0 \pm 104.3^{*}$ & $214.0 \pm 35.4$ \\
$(50-196) \mathrm{mg} / \mathrm{dl}$ & & $(68-423) \mathrm{mg} / \mathrm{dl}$ &
\end{tabular}

\section{Discussion}

Chronic Otitis Media (COM) cases are more common than (AOM), and that can be attributed to the fact that OM infections are the most common consequences after Respiratory Tract Infections (RTI). This opinion is in agreement with. ${ }^{1}$ They found in a study done in Pittsburgh hospital that the chronic infections with effusion are more common than the AOM especially in winter outbreaks, which was also supported by. ${ }^{12}$ Concerning total W.B.C.s results, OM infection caused elevation in total W.B.C.s count; these outcomes can due to OM infection after
RTIs. Whereas RTI lead to elevation of total Leukocytes count as stated by. ${ }^{13}$ That was also in documented by. ${ }^{11}$

The outcomes of Immunoglobulin's estimation showed that OM caused increase IgG and IgM values and that can be explained by the induction of HMI, OM bacterial infections lead to rise Immunoglobulin levels due to specific Abs production especially when the infections were caused by the pathogens Staphylococcus aureus and Streptococcus pneumoniae, that was in consistent with the opinions of both. ${ }^{14,15}$ 


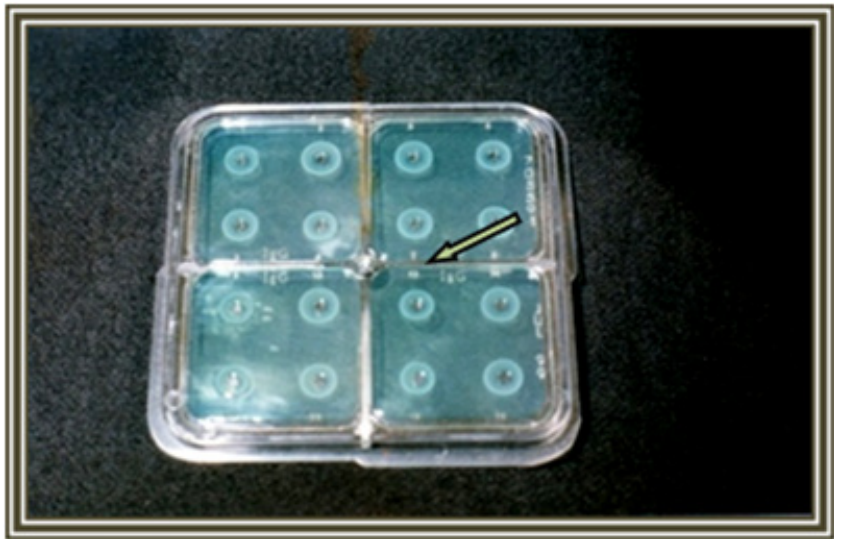

Figure I The Endoplate Kit (Radial Immune Diffusion, RID), showing precipitation zones obtained.Arrow shows a control well.

Also ${ }^{16}$ pointed to the fact that bacterial OM caused by encapsulated Streptococcus pneumoniae usually causes elevation in IgM value because this type of antibodies is effective during immune response against bacterial capsules and there were $11(18.3 \%)$ patients in the present research whom had the same causative pathogen. The type IgA immunoglobulins represents the first line of defense against bacterial colonization in mucosal surfaces in the Upper Respiratory Tract. That because the subclass secretary sIgA antibodies are able to be secreted with mucus and share with other factors in local immune response against pathogens colonization in the middle ear. ${ }^{7,17}$

The results of IgA levels were as expected all PGs levels increased except PG1. This group IgA levels decreased insignificantly that can be attributed to that this group represents children under the age 10 years. The members of this group are more prone to bronchiolitis and other RTI during winter outbreaks. ${ }^{18}$ Moreover Eustachian tube mucosa in children is less differentiated and differs from adults as mentioned by. ${ }^{19,20}$

Complement components $\mathrm{C} 3$ and $\mathrm{C} 4$ increased in OM patient's blood because of the important role of these complement components in the inflammatory process during infections, these results are also documented by ${ }^{21}$ they fully described complement role in the middle ear infections and they attributed that increase to the increase of the complement and inflammatory mediators production during inflammation of middle ear after activation of phagocytic cells. The authors ${ }^{7,22}$ stated that many complement proteins and Cytokines levels usually rise during inflammatory diseases as a part of innate immunity and as a start of specific Humoral response and that is supporting to the findings of our study.

\section{Conclusion}

Otitis media is a common infection in both children and adults epically after winter season. Gram positive suppurative OM caused; in imunologically uncompromised patients; significant elevations in Total W.B.C.s counts, Immunoglubulins IgG, IgM and IgA and the complement components $\mathrm{C} 3$ and $\mathrm{C} 4$ due to induction of $\mathrm{HMI}$ response against these infections.

\section{Acknowledgments}

Special thanks to Dr. Rajwa H. Al-Rubaei (Dep. Bio. Coll. Sci. Al-Mustansiriya Univ.) And to Dr. Hamid M. Ghani (let the mercy of God be upon him). I am grateful to Al-Nuaman Hospital ENT Dep, and the inner and outer Laboratories staff. I am much obliged to patients and healthy volunteers.

\section{Conflicts of interest}

Author declares there are no conflicts of interest.

\section{Funding}

None.

\section{References}

1. Rayner MG, Zhang Y, Gorry MC, et al. Evidence of Bacterial metabolic activity in culture- Negative otitis media with effusion. JAMA 1998;279(4):296-290

2. Tarlow M. Otitis Media: Pathogenesis and Medical sequelae. Ear Nose Throat. 1998;77(6 Suppl):3-6.

3. Tapiainen $\mathrm{T}$, Kujala $\mathrm{T}$, Kaijalainen $\mathrm{T}$, et al. Biofilm formation by Streptoccus preumoniae isolates from paediatric patients. APMIS. 2010;118(4):255-260.

4. Al-Hamadany W. Isolation and Identification of Gram Positive Cocci Bacterial Pathogens from Suppurative Otitis Media Infections. Iraqi Journal of Veterinary Medicine. 2013;37(1):129-133.

5. Altemeier WA. A Trip through the ear in search of deafness. Pediatric Ann. 1999;28(6):342-344.

6. Mashchenko A, Mashkova T. Diagnostic criteria for surgical correction of exudative Otitis Media in children. Vestn Otorinolaringol 2010;5:56-57.

7. Delves PJ, Martin SJ, Burton DR, et al. Roitt's Essential Immunology. (11th edn), Blackwell publishing Ltd., USA. 2006.

8. Houghton D, White P, Browning G. Predictors of outcome in children with otitis media with effusion. Clin Otolaryngol Allied Sci . 1998;23(1):48-50.

9. Lewis S, Bain BJ, Bates I, et al. Dacie and Lewis: Practical Hematology. (11th edn), Elsevier Ltd. Churchill Livingstone. Germany. 2011

10. Statistical Analysis System (SAS). SAS/Stat user guide for personal computer. Release 6.12 SAS Institute. Inc. Cary. N. C. USA. 2000.

11. Mckenzie SB. Clinical Laboratory Hematology. Pearson Education, Inc. USA. 2004

12. Vartianen, A, Vartianen J. Effect of aerobic Bacteriology on the clinical presentation and treatment results of chronic suppurative otitis media. $J$ Laryngol Otol. 1996;110(4):315-318.

13. Mittal R, Lisi CV, Gerring R, et al. Current Concepts in the Pathogenesis and Treatment of Chronic Suppurative Otitis Media. J Med Microbiol. 2005;64(10):1103-1116

14. Ruben RJ. Serous Otitis Media in the 20th and 21st centuries: evolving views and treatments. Acta Otolaryngol 129(4): 343-347.

15. Wysocka J, Zelazowska-Rutkowska B, Ratomski K, Skotnicka B, Hassmann-Poznańska E (2009) Evaluation of Lymphocytes B with expression of co-receptors CD40, CD22 and CD72 in hypertrophied adenoid at children with Otitis Media with effusion. Otolaryngol Pol. 2009;63(6):504-508.

16. Albrecht T. Medical Microbiology: Guide Textbook. Library of Congress pub. USA. 2008

17. Bernstein JM, Reddy MS, Scannapieco FA, et al. The microbial Ecology and Immunology of adenoid: Implications for otitis media. Ann $N Y$ Acad Sci. 1997;830:19-31.

18. Elsayed Yousef Y, Abo El-Magd EA, El-Asheer OM, et al. Impact of Educational Program on the Management of Chronic Suppurative Otitis Media among Children. Int J Otolaryngol . 2015;2015:624317. 
19. Chao W, Chang S. Ultrastracture of Eustachian tube mucosa in chronic otitis media with cholesteatoma. AMJOtolaryngol. 1996;17(3):161-166.

20. Ivady B, Pasztor M. Serotype distribution and antimicrobial ssusceptibility of streptococcus preumoniae strain isolated from middle ear fluids of children aged 0-24 months with acute Otitis Media. Orv Hetil. 2009; 150(20):935-941.
21. Mittal R, Kodiyan J, Gerring R, et al. Role of Innate Immunity in the Pathogenesis of Otitis Media. Int J Infect Dis. 2014;29:259-267.

22. Edgar JD. Immunology: Mastt edn), Elsevier Churchill Livingstone Pub. China. 2006. p. 208. 